\title{
The impact of sharps injuries on student nurses: a systematic review
}

\author{
Hambridge, Kevin
}

http://hdl.handle.net/10026.1/12609

10.12968/bjon.2016.25.19.1064

British Journal of Nursing

Mark Allen Healthcare

All content in PEARL is protected by copyright law. Author manuscripts are made available in accordance with publisher policies. Please cite only the published version using the details provided on the item record or document. In the absence of an open licence (e.g. Creative Commons), permissions for further reuse of content should be sought from the publisher or author. 


\title{
The impact of sharps injuries on student nurses: a systematic review
}

\author{
Kevin Hambridge, Andrew Nichols and Ruth Endacott
}

\begin{abstract}
Aims and objectives: The purpose of this review was to discover the impact of sharps injuries in the student nurse population. Background: much is known and reported about sharps injuries in registered nurses, but there has been a lack of published evidence regarding sharps injuries within the student nurse population. Method: A systematic review of nursing, health and psychology databases was conducted. The limits set were publications between 1980 and 2014 in the English language. Studies were identified then, following a rigorous critical and quality appraisal with validated tools, were selected for the systematic review. Results: A total of 40 articles met the inclusion criteria, reporting studies conducted in 18 countries. Psychological and physical impacts of sharps injuries in student nurses were reported, such as fear, anxiety and depression, although these impacts were not quantified using a validated instrument. Conclusion: The impact of sharps injuries can be severe, both psychological and physical. This systematic review shows that further research is needed into this, especially in under-researched areas such as the UK, to establish the impact of sharps injuries within this population. Further research would also aid the education and prevention of this harmful problem. The review also emphasises the psychological issues relating to sharps injuries, the impact these can have on individuals and the support and counselling that student nurses require after injury. Relevance to practice: These findings highlight the potential psychological issues that can result from sharps injuries in this population
\end{abstract}

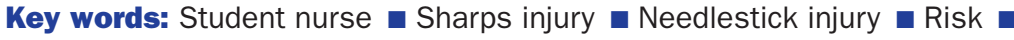

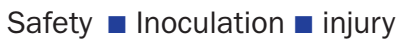

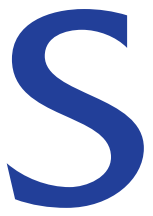

harp devices, or sharps, are items capable of piercing the skin and include needles, surgical instruments, lancets, scalpels and glass (Hersey and Martin, 1994; Bandolier, 2003; World Health Organization, 2003). Sharps injuries are one of the main categories of accidents experienced by healthcare staff, and have been described as an 'important public health concern' (Pathak et al, 2012: 639).

Kevin Hambridge, Lecturer in Adult Nursing and Admissions Tutor for Adult Nursing, Plymouth University

Andrew Nichols, Lecturer in Nursing Studies, Plymouth University

Ruth Endacott, Professor in Clinical Nursing (Critical Care), Plymouth University

Accepted for publication: August 2016
Sharps injuries are not a recent phenomenon. During the 1990s, warnings were made about hazards and risks of sharps injuries (Yassi and McGill, 1991), with Albertoni et al (1992: 541) arguing that occupational exposure to infectious agents had been a significant concern 'for some time'. In today's diverse healthcare environments, most employees run the risk of accidental exposure to blood and bloodborne pathogens.

More than 20 bloodborne pathogens can be transmitted through percutaneous injuries (Collins and Kennedy, 1987; Morgan, 2000). More recently, this estimation was increased to at least 60 pathogens (Tarantola et al, 2006). The three most common bloodborne pathogens that can be transmitted via percutaneous injuries to healthcare workers are: the human immunodeficiency virus (HIV); the hepatitis B virus (HBV); and the hepatitis $\mathrm{C}$ virus (HCV) (Jayanth et al, 2009).

Every sharps injury has potentially severe consequences for the staff member, causing 'distress' and 'physical damage' at the very least (Watterson, 2004). Reis et al (2004a) described how students exposed to biological hazards experience not only the fear of acquiring potential infections such as HIV, HBV and HCV, but also had feelings of 'insecurity' and 'low self-esteem'. This is echoed by Gupta et al (2008), who found that sharps injuries can have an effect on healthcare workers' quality of life, and can cause great apprehension, angst and fear for themselves, their family and their colleagues, as well as feelings of shame and low self-confidence (Gonzalez-Medina and Le, 2011).

Sharps injuries have other effects, including the direct cost, for example post-exposure medical treatment and resources, as well as indirect costs, such as disability, missed work days and absenteeism (Sharma et al, 2010; Bassil, 2012). There is also an economic impact on the individual (Trueman et al, 2008).

In relation to student nurses, the prevalence rates of sharps injuries range from $3 \%(n=6)(\mathrm{Li}$ et al, 2008) to $100 \%(n=100)$ (Trivedi et al, 2013). Undergraduate healthcare students often handle piercing/cutting devices while training, which exposes them to the risk of acquiring infections (Gir et al, 2008). They are at a high risk of exposure to bloodborne pathogens when they become involved in patient investigations and treatments during their clinical placements (Hussain et al, 2012). By their very nature of being students, they are less experienced (Karadağ, 2010; Reis et al, 2004b) in the clinical setting and less skilful (Cheung et al, 2010) when handling needles and sharps, which exposes them to potential injury.

Other possible reasons put forward to explain the increased risk of sharps injury student nurses are insufficient attention to 
personal safety (Cheung et al, 2012), manual skills that are under-developed (Ozer and Bektas, 2012), eagerness to learn new procedures (Karadağ, 2010; Ozer and Bektas, 2012) and anxiety (Reis et al, 2004b).

The extent, type and impact of sharps injuries among preregistration student nurses was chosen as a topic to explore because authors have argued that there is a dearth of evidence and published studies related to this subject (Hou and Shiao, 2001; Elliott et al, 2005; Blackwell et al, 2007; Petrucci et al, 2009; Karadağ, 2010; Hambridge, 2011).

\section{Methods}

The question asked in this systematic review is: 'What are the extent, type and impact of sharps injuries in the pre-registration nursing student population?' As of 2014, an extensive research of the literature found no systematic review on this topic.

This systematic review was conducted in six stages:

- Development of the search strategy with inclusion and exclusion criteria

- Search for articles

- Screening of articles

- Critical appraisal of the articles

- Data extraction from the chosen articles

- Aggregation of the data.

A comprehensive search of nursing, health and psychology databases was undertaken, which included: BMJ Journals collection; Business Source Complete (EBSCO); CINAHL Plus with Full Text (EBSCO); BMJ Clinical Evidence; the Cochrane Library (Wiley); Internurse; Medline (EBSCO); PubMed; PsycArticles, PsycINFO; ScienceDirect; SwetsWise; Trip (Turning research into practice); and UK PubMed Central.

Relevant studies were also identified by searching the following grey literature databases: the National Research Register; Clinicaltrials.gov; Google Scholar; Sigle; theses and dissertations (UK and worldwide); the PQDT (open); and EThOS (British Library Electronic online service).The Intute, Department of Health, NHS, Monitor (regulator for health services in England), Health Protection Agency, Centers for Disease Control and Prevention and Trove (finding Australian theses) websites were also searched.

Keywords were chosen to aid the retrieval of pertinent articles. Those used were 'adult student nurse', 'pre-registration', 'student of nursing', 'student nurse', 'sharp injury', 'sharps', 'sharp injuries', 'needlestick', 'needlestick injury', 'needlestick injuries', 'inoculation', 'needle prick', 'accidents', 'incidents', 'needle stick', 'occupational injury', 'occupational injuries', 'biological exposure incident', 'percutaneous exposure', 'blood borne infection', 'incidence', 'prevalence','harm', 'psychological harm', 'experiences' ,impact', 'under-reporting', 'non-reporting', 'RCT', 'survey', 'case study', 'ethnography', 'action research', 'phenomenology', 'qualitative', 'experimental design (pre-post)' ت and 'mixed methods designs'.

The inclusion criteria were related to pre-registration student nurses who had experienced a sharps injury, including needlestick injuries. This systematic review included all studies relating to sharps injuries that affected these students caused by needles, scalpels and blades, suture and stitch cutters, blood lancets, glass, scissors and razors. Articles published worldwide from 1980 to 2014 were included. This is because AIDS was first recognised as a disease in 1981 (Sharp and Hahn, 2011) and there is a relationship between AIDS and HIV and sharps injuries.

Both quantitative and qualitative studies were examined for inclusion. The quantitative component of the review considered experimental study designs including randomised controlled trials, non-randomised controlled trials, quasi-experimental, before and after studies, prospective and retrospective cohort studies, case control studies, analytical cross-sectional studies, epidemiological study designs including case series, individual case reports and descriptive cross-sectional studies.

The qualitative component of the review considered studies that focus on qualitative data, including phenomenology, grounded theory, ethnography and action research.

Original articles and review articles, including systematic and narrative reviews, were considered. The exclusion criteria were: articles not published in English; articles with a focus on self-harm, or the effect of an injury on a patient; and articles reporting an audit or quality improvement project.

The screening process was conducted in three distinct stages:

- Based on the title

- Based on the abstract

- Based on the full text.

The search identified 190 articles; following screening, 40 articles were eligible for inclusion in the review. The process is shown in Figure 1.

It was imperative to appraise the quality and relevance of the articles to decide whether the findings could be included in this review.After studies of an acceptable design were selected, an in-depth assessment for the risk of various biases was conducted. Critical and quality appraisal of the potential studies was conducted using tools appropriate to the study method.

Systematic reviews were appraised using the ' 10 questions to help you make sense of a review' critical appraisal tool (Critical Appraisal Skills Programme (CASP), 2013). Evidence for the tool's effectiveness is scarce but it has been recommended by the National Institute for Health and Care Excellence (2014).

Papers employing a survey were assessed using the Crombie framework (Crombie, 1996), a checklist suitable for appraising descriptive surveys (Holly, 2010).

Qualitative articles were assessed using the CASP (2006). This tool has been widely used, allows rapid evaluation and is suitable for different types of qualitative design (Ricci-Cabello et al, 2012).

The case study included in this review was critically appraised using the Critical Appraisal of a Case Study tool (Centre for Evidence-Based Management, 2013). Evidence for its effectiveness is scarce but its use has been promoted by the Centre for Evidence Based Medicine (2014).

The Support Unit for Research Evidence tool for critically appraising intervention/experimental and controlled observation studies was used to appraise quasi-experiments (Cardiff University, 2012).

Quantitative data were extracted from papers using the MAStARI data extraction instrument, while qualitative data was 


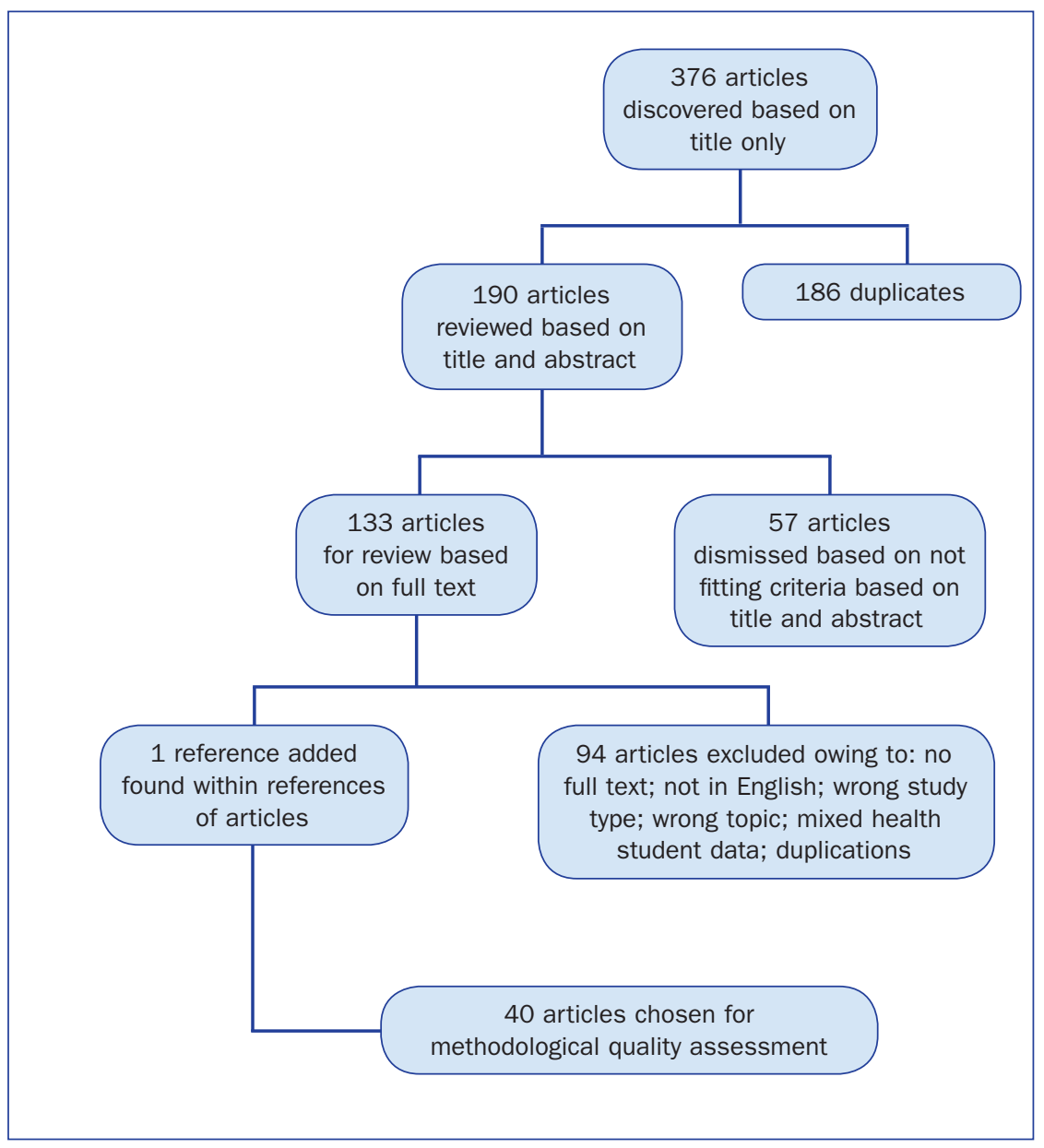

Figure 1. Process of article selection

\section{Reaction to the traumatic incident}

The respondents spoke of their 'physiological reaction' to the sharps injury. These responses included being 'shocked', 'sweating', wanting to 'run away and scream', 'tears' and 'crying'. There were reports of the 'emotional reaction of the student and family'. Reactions included being 'fearful of becoming HIV positive', having an 'out of body experience' and feeling 'overwhelming fear', 'anxiety', 'depression' and 'numb'.

The respondents reported a 'lack of care from the staff in the service setting', with some staff being 'very unsympathetic'. The incident was defined as being 'nerve wracking', with associated 'blame from family'. It was reported that one respondent's 'family was angry' and 'didn't talk to me for the rest of the day'.

Respondents reported the 'reaction to treatment' including the side effects of the post-exposure prophylactic drugs, such as sickness, dizziness and nausea, which affected their attendance at university and on the practice placement.

Respondents spoke of the 'reaction to nursing practice' whereby they felt distressed when re-entering the practice placement as they felt they were 're-living the injury'. One respondent said they would have considered suicide if seroconversion occurred. One student still felt 'numb' 2 months after the sharps injury, fearing they may have acquired HIV.

\section{Intervening factors}

A lack of awareness about sharps injury reporting among respondents was described.Two nursing students did not report their injuries because of the "negative support and unavailability of the nursing staff'. Respondents reported poor knowledge of registered nurses concerning treatment and counselling after a sharps injury. This caused a delay in treatment and a lack of counselling support for some students. Some respondents reported that, owing to their 'submissive behaviour', they commonly carried out procedures that were outside their scope of practice, which may have contributed to the sharps injuries.

extracted from papers using the JBI QARI data extraction for interpretive and critical research (Joanna Briggs Institute, 2014).

\section{Results}

In total, 40 studies met the inclusion criteria for the systematic review: 34 surveys; 4 quasi-experiments; 1 case study; and 1 qualitative study (Table 1 ). Some studies reported data from a range of healthcare students; where possible, data for student nurses were extracted and are reported here.

\section{Impact of sharps injuries}

Only one study explored the experiences of student nurses who had sustained sharps injuries. Naidoo (2010) used a qualitative phenomenological approach with a sample of eight student nurses in South Africa. From the study, four themes were reported: traumatic incident; reaction to the traumatic incident; intervening factors; and need for support.

\section{Traumatic incident}

Student nurses gave an 'account of the incident'; they provided rich detail even though the incident may have happened up to a year previously. They knew the precise date and time of the sharps injury. The students also described how the injury transpired by 'setting the scene'.

\section{Need for support}

Respondents generally spoke of supportive family and friends, who were described as 'sympathetic' and 'supportive'. Some respondents felt that some nursing staff in the practice setting were not supportive. However, the clinical supervisors from the higher education institute were 'excellent'. Students felt 'guided' through the system and were directed to counselling offered by the university.

One other study provided qualitative data on the consequences of the sharps injury on students. Reis et al (2004b) described how they reported negative feelings of 'anger', 'insecurity', 'concern', 'fear', 'low self-esteem', 'frustration', 'incapacity', 'incompetence' and 'fear of infection e.g. HIV' following a sharps injury.

None of the studies sought to examine the impact of having a sharps injury using a validated instrument to measure anxiety or depression.

\section{Discussion}

A total of 40 papers were reviewed.The main area of investigation was the impact of sharps injuries in a pre-registration adult branch nursing student population. 


\section{Impact of sharps injuries}

The single qualitative study investigating the experiences of nursing students who had sustained sharps injuries (Naidoo 2010) highlighted the feelings of 'fear [and] anxiety' experienced by nursing students who had sustained a sharps injury in South Africa. This is echoed by Lee et al (2005), who found in a review of prospective studies that healthcare workers experience significant fear, anxiety and emotional distress following a needlestick injury, sometimes resulting in occupational and behaviour changes. Sustaining a sharps injury is stressful, and the higher rates of anxiety in these practitioners could put them at a higher risk of future sharps injuries (Sohn et al, 2006). Meanwhile, Zhang and Yu (2013) reported that 15.2\% of healthcare workers recounted manifestations of emotional distress, such as anxiety, worry, frustration, panic and even extremity numbness after experiencing a sharps injury.

In a study of trainee doctors, Naghavi et al (2013) found that sharps injuries are associated with human costs in terms of stress and anxiety, and persistent symptoms could meet the diagnosis criteria for post-traumatic stress disorder. They also found that $12 \%$ of doctors who had experienced at least one needlestick injury during their training reported symptoms consistent with post-traumatic stress disorder. Worthington et al (2006) reported two cases of post-traumatic stress disorder after needlestick injuries to two doctors from an HIV-positive patient.

Occupational exposure to bloodborne pathogens can be a frightening experience; healthcare workers may be scared and a few might develop long-term psychiatric consequences (Gerberding, 2003). Student nurses talked of 'depression' and feeling like a 'huge cloud over my head' after a sharps injury; as mentioned above, one had considered suicide if seroconversion occurred (Naidoo, 2010).

Student nurses' fear of becoming HIV positive (Reis et al, 2004b; Naidoo, 2010) is mirrored by Zhang and Yu (2013), who reported that $93.9 \%$ of healthcare workers indicated that the major factor inducing negative psychological changes was the fear of HIV infection.

Respondents in the study by Naidoo (2010) spoke of their 'need for support', with many praising supportive family, friends and clinical supervisors but saying that nursing staff were not as sympathetic and there appeared to be a 'lack of counselling support'. Zhang andYu (2013) concluded that discovering the ideal type, content and timing of psychological interventions is crucial to lessen anxiety in healthcare workers who sustain a needlestick injury.

Wicker et al (2014) stated that understanding of the psychological impact of needlestick injuries is limited because published studies are scarce, while Zhang andYu (2013) contend that published research into the psychological impact of sharps injuries is limited, compared to studies into the incidence,

I situations when it happens, risk factors and economic costs.

Great efforts are made to prevent needlestick and sharps injuries, but the psychological aspects of these injuries have received little attention (Sohn et al, 2006).

It appears there are potentially huge psychological issues for practitioners following a sharps injury, with only one qualitative

\section{KEY POINTS}

- Sharps injuries can have severe, lasting psychological and physical effects

- Students are at risk of these injuries because they are less skilful and experienced, are eager to learn new procedures or because a submissive nature means they carry out procedures outside their scope of practice

- After a sharps injury, student nurses experience fear, anger, numb, low selfesteem, insecurity, anxiety, depression and fear of infection, especially with HIV

- Support was commonly given by friends, family and higher education institutions but rarely by nurses

- Only one qualitative study explored the effect of a sharps injury on student nurses; it is therefore an under-researched area

- Further research in this area would help to prevent sharps injury the education and prevention of this harmful problem

study found that explored the potential impact on student nurses. This is therefore an under-researched area which requires further investigation.

\section{Conclusion}

This systematic review identified gaps in understanding and shows that further research is needed into this topic, especially in surprisingly under-researched areas of the world such as the UK. Further research would also further aid education and the assessment and management of risks.

The findings also emphasise the psychological issues relating to sharps injuries, the impact they can have and the support and counselling that students nurses require after an injury. BJN

\section{Declaration of interest: none}

A more comprehensive table looking at the 40 studies included in the review is available from the Editor.

Albertoni F, Ippolito G, Petrosillo N et al (1992) Needlestick injury in hospital personnel: a multicenter survey from central Italy. The Latium Hepatitis B Prevention Group. Infect Control Hosp Epidemiol 13(9): 540-4

Askarian M, Malekmakan L, Memish ZA, Assadian O (2012) Prevalence of needle stick injuries among dental, nursing and midwifery students in Shiraz, Iran. GMS Krankenhhyg Interdiszip 7(1): doc05. doi: 10.3205/ dgkh000189

Aslam M, Taj T, Ali A, Mirza W, Ali H, Dar M, Badar N (2010) Needle stick injuries among health care workers of public sector tertiary care hospitals of Karachi.J Coll Physicians Surg Pak 20(3): 150-3. doi: 03.2010/ JCPSP.150153

Bandolier (2003) Needlestick injuries. Bandolier Extra. July. http://tinyurl. com/6eq9q6 (accessed 23 August)

Bassil, AA (2012) Sharps safety in hospitals. Hum Health 18: 12-16

Blackwell LBJ, Bolding J, Cheely E et al (2007) Nursing students' experiences with needlestick injuries.J Undergrad Nurs Scholarsh Fall 9

Joanna Briggs Institute (2014) JBI QARI Data Extraction for Interpretive \& Critical Research. http://tinyurl.com/hdwzelo (accessed 23 August 2016)

Cardiff University (2012) SURE Critical Appraisal Checklists. http://tinyurl. com/h77uxgu (accessed 23 August 2016)

Critical Appraisal Skills Programme (2006) Critical Appraisal Skills Programme. Making Sense of Evidence. www.casp-uk.net (accessed 23 August 2016)

Critical Appraisal Skills Programme (2013) Critical Appraisal Skills Programme. Making Sense of Evidence www.casp-uk.net (accessed 23 August 2016)

Centre for Evidence-Based Management (2013) Critical Appraisal. http:// tinyurl.com/hq4p9m4 (accessed 29 August)

Centre for Evidence Based Medicine (2014) Study Designs. http://tinyurl. com/zlc6du7 (accessed 23 August 2016) 
Cheung K, Ho SC, Ching SS, Chang KK (2010) Analysis of needlestick injuries among nursing students in Hong Kong. Accid Anal Prev 42(6): 1744-50. doi: 10.1016/j.aap.2010.04.015

Cheung K, Ching SSY, Chang KKP, Ho SC (2012) Prevalence of and risk factors for needlestick and sharps injuries among nursing students in Hong Kong. Am J Infect Control 40(10): 997-1001. doi: 10.1016/j. ajic.2012.01.023

Collins CH, Kennedy DA (1987) Microbiological hazards of occupational needlestick and 'sharps' injuries. J Appl Bacteriol 62(5): 385-402

Crombie I (1996) The Pocket Guide to Critical Appraisal. BMJ Publishing Group, London

Elliott SK, Keeton A, Holt A (2005) Medical student knowledge of sharps injuries. J Hosp Infect 60(4): 374-7. DOI: 10.1016/j.jhin.2005.01.033

Gerberding JL (2003) Occupational exposure to HIV. N Engl J Med 349(12): 1091-2. DOI: 10.1056/NEJM200309113491119

Gir E, Netto JC, Malaguti SE, Canini S, Hayashida M, Machado AA (2008) Accidents with biological material and immunization against hepatitis B among students from the health area. Rev Lat Am Enfermagem 16: 3. http:// dx.doi.org/10.1590/S0104-11692008000300011. http://tinyurl.com/ h69686n

Gonzalez-Medina D, Le QV (2011) Infectious diseases and interpersonal trust: international evidence. Health 3(4): 206-10. doi: 10.4236/ health.2011.34037

Gupta A, Anand S, Sastry J et al (2008) High risk for occupational exposure to HIV and utilisation of post-exposure prophylaxis in a teaching hospital in Pune, India. BMC Infect Dis 8: 142. doi: 10.1186/1471-2334-8-142

Hambridge K (2011) Needlestick and sharps injuries in the nursing student population. Nurs Stand 25(27): 38-45. doi: 10.7748/ns2011.03.25.27.38. c8389

Hersey JC, Martin LS (1994) Use of infection control guidelines by workers in healthcare facilities to prevent occupational transmission of HBV and HIV: results from a national survey. Infect Control Hosp Epidemiol 15(4 Pt 1): 243-52

Holly CPL (2010) A comprehensive systematic review of adult users attitudes and beliefs regarding herbal and food supplements for the relief of chronic pain. JBI Library of Systematic Reviews 8(34): 1-26. doi: 10.11124/ jbisrir-2010-680. http://tinyurl.com/hnvw4hf

Hou JY, Shiao JSC (2001) Needlestick injuries among Final Year Student Nurses from one area of Southern Taiwan. Chin J Occup Med (In Chinese, English abstract) 8(2): 79-85

Hussain JSA, Ram SM, Galinde J, Jingade RRK (2012) Occupational exposure to sharp instrument injuries among dental, medical and nursing students in Mahatma Gandhi Mission's Campus, Navi Mumbai, India. J Contemp Dent 2(2): 1-10. doi: 10.5005/jp-journals-10031-1001

Irmak Z, Baybuga MS (2011) Needlestick and sharps injuries among Turkish nursing students: A cross-sectional study Int J Nurs Practice 17(2): 151-7. doi/10.1111/j.1440-172X.2011.01920.x

Jayanth ST, Kirupakaran H, Brahmadathan KN, Gnanaraj L, Kang G (2009) Needle stick injuries in a tertiary care hospital. Indian J Med Microbiol 27(1): 44-7

Karadağ M (2010) Occupational exposure to blood and body fluids among a group of Turkish nursing and midwifery students during clinical practise training: frequency of needlestick and sharps injuries. Jpn J Nurs Sci 7(2): 129-35. doi: 10.1111/j.1742-7924.2010.00148.x

Kermode M, Jolley D, Langkham B, Thomas MS, Crofts N (2005) Occupational exposure to blood and risk of bloodborne virus infection among health care workers in rural north Indian health care settings. Am Infect Control 33(1): 34-41. doi: 10.1016/j.ajic.2004.07.015

Kim KM, Kim MA, Chung YS, Kim NC (2001) Knowledge and performance of the universal precautions by nursing and medical students in Korea. $A m$ J Infect Control 29(5): 295-300

Lachowicz R, Mathews PA (2009) The pattern of sharps injury to health care workers at Witbank Hospital. S Afr Fam Pract 51(2): 148-51. doi: $10.1080 / 20786204.2009 .10873831$

Lee JM, Bottleman MF, Xanthakos N, Nicklasson L (2005) Needlestick injuries in the United States. Epidemiologic, economic and quality of life issues. $A A O H N J \mathbf{5 3}(3): 117-33$

Li Y, Scott CS, Li L (2008) Chinese nursing students' HIV/AIDS knowledge, attitudes, and practice intentions. Appl Nurs Res 21(3): 147-52. doi: 10.1016/j.apnr.2006.10.004

Lukianskyte R, Gataeva J Radziunaite L (2011) Needle sticks and sharps injuries experienced by staff nurses and nursing students and their prevention. Int J Infect Control 8(1): 3-9. doi: http://dx.doi.org/10.3396/ ijic.v8i1.8961

McCarthy GM Britton JE (2000) A survey of final-year dental, medical and nursing students: occupational injuries and infection control.J Can Dent Assoc 66(10): 561.

Mengal, HU, Howteerakul, N Suwannapong, N Rajatanun, T (2008) Factors relating to acceptance of hepatitis $\mathrm{B}$ virus vaccination by nursing students in a tertiary hospital, Pakistan.J Health Popul Nutr 26(1): 46-53
Mitra SP, Mallik S, Das M, Roy AS (2010) Injection safety: perception and practice of nursing students in tertiary setting Ind J Prev Soc Med 41(3-4 Muralidhar S, Singh PK, Jain RK, Malhotra M, Bala M (2010) Needle stick injuries among health care workers in a tertiary care hospital of India. Indian J Med Res 131: 405-10

Morgan DR (2000) Missing the point: a review of needle-stick injury and occupational risks from blood-borne viruses. Appl Biosaf 5(2): 47-53

Naghavi SH, Shabestari O, Alcolado J (2013) Post-traumatic stress disorder in trainee doctors with previous needlestick injuries. Occup Med (Lond) 63(4): 260-5. doi: 10.1093/occmed/kqt027

Naidoo M (2010) Experiences of the University of the Western Cape Student Nurses Who Sustain Needle-Stick Injuries During Their Clinical Placement. Minithesis for the degree of Magister Curationis. School of Nursing, Faculty of Community and Health Sciences, University of the Western Cape. http:// tinyurl.com/j1766mq (accessed 29 August 2016)

National Institute for Health and Care Excellence (2014) CASP Tools. NICE, London. http://tinyurl.com/jfdyq3u (accessed 23 August 2016)

Ozer ZC, Bektas HA (2012) Needlestick injuries during education period in nursing students in Turkey. Procedia Soc Behav Sci 46: 3798-801. doi: 10.1016/j.sbspro.2012.06.149

Pathak R, Kahlon AS, Ahluwalia S, Sharma S, Bhardwaj R (2012) Needle stick injury and inadequate post exposure practices among health care workers of a tertiary care centre in rural India. Int J Collab Res Intern Med Public Health 4(5): 639

Petrucci C, Alvaro R, Cicolini G, Cerone M, Lancia L (2009) Percutaneous and mucocutaneous exposures in nursing students: an Italian observational study. J Nurs Scholarsh 41(4): 337-43. doi: 10.1111/j.15475069.2009.01301.x

Reis RK, Gir E, Canini SR (2004a) Accidents with biological material among undergraduate nursing students in a public Brazilian University. Braz J Infect Dis 8(1): 18-24. doi: 10.1590/S1413-86702004000100003

Reis RK, Gir E, Canini SR (2004b) Accidents with biological material among undergraduate nursing students in a public Brazilian university. Braz J Infect Dis 8(1): 18-24. doi: /S1413-86702004000100003

Ricci-Cabello, I Gonçalves, DC Campbell, SM Slight, SP Valderas JM (2012) Patient Experiences of Patient Safety in Primary Care in England. A Systematic Review and Meta-Synthesis. Seminar presentation. http://tinyurl.com/ hsfrblk (accessed 29 August 2016)

Salelkar S, Motghare DD, Kulkarni MS,Vaz FS (2010) Study of needle stick injuries among health care workers at a tertiary care hospital. Indian J Public Health 54(1): 18-20. doi: 10.4103/0019-557X.70540

Scaggiante R, Chemello L, Rinaldi R, Bartolucci GB, Trevisan A (2013) Acute hepatitis $\mathrm{C}$ virus infection in a nurse trainee following a needlestick injury. World J Gastroenterol 19(4): 581-5. doi: 10.3748/wjg.v19.i4.581.

Schaffer S (1997) Preventing nursing student exposure incidents: the role of personal protective equipment and safety engineered devices. J Nurs Educ 36(9): 416-20.

Schmid K, Schwager C, Drexler H (2007) Needlestick injuries and other occupational exposures to body fluids amongst employees and medical students of a German university: incidence and follow-up. J Hosp Infect 65(2): 124-30. doi: 10.1016/j.jhin.2006.10.002

Sharma R, Rasania SK, Verma A, Singh S (2010) Study of prevalence and response to needlestick injuries among health care workers in a tertiary care hospital in Delhi, India. Indian J Community Med 35(1): 74-7. doi: 10.4103/0970-0218.62565

Shiao JM, Huang KY, Guo YL (2002) Student nurses in Taiwan at high risk for needlestick injuries. Ann Epidemiol 12(3): 197-201

Sharp P Hahn BH (2011) Origins of HIV and AIDS pandemic. Cold Spring Harb Perspect Med 1(1): a006841. doi: 10.1101/cshperspect.a006841

Small L, Pretorius L, Walters A, Ackerman MJ (2011) A surveillance of needlestick injuries amongst student nurses at the University of Namibia. Health SA Gesondheid 16(1): 8 pages. doi: 10.4102/hsag.v16i1.507

Smith DR, Leggat PA (2005) Needlestick and sharps injuries among nursing students. J Adv Nurs 51(5): 449-55. doi: 10.1111/j.13652648.2005.03526.x

Sohn JW, Kim BG, Kim SH, Han C (2006) Mental health of healthcare workers who experience needlestick and sharps injuries.J Occup Health 48(6): 474-9

Talas MS (2009) Occupational exposure to blood and body fluids among Turkish nursing students during clinical practice training: frequency of needlestick and sharp injuries and hepatitis B immunisation. J Clin Nurs 18(10): 1394-403. doi: 10.1111/j.1365-2702.2008.02523.x

Tetali S Choudhury P (2006) Occupational exposure to sharps and splash: Risk among health care providers in three tertiary care hospitals in South India. Indian J Occup Environ Med 10(1): 35-40. doi: 10.4103/00195278.22894

Tarantola A, Abiteboul D, Rachline A (2006) Infection risks following accidental exposure to blood or body fluids in health care workers: a review of pathogens transmitted in published cases. Am J Infect Control 34(6): 367-75. doi: 10.1016/j.ajic.2004.11.011 
Trivedi A, Kasar PK, Tiwari R,Verma P, Sharma A (2013) An educational intervention programme for prevention and management of needle stick injuries among nursing students at a tertiary care hospital, Jabalpur, Madhya Pradesh. Community Med 4(1): 132-6

Trueman P,Taylor M, Twena N, Chubb B (2008) The cost of needlestick injuries associated with insulin administration. Br J Community Nurs 13(9): 413-7. doi: 10.12968/bjcn.2008.13.9.30911

UnverV,Tastan S, Coskun H (2012) The frequency and causes of occupational injuries among nursing students in Turkey. Arch Environ Occup Health 67 (2): 72-7. doi: 10.1080/19338244.2011.573024

Vandijck D, Labeau S, De Somere J, Claes B, Blot S; Executive Board of the Flemish Society of Critical Care Nurses (2008) Undergraduate nursing students' knowledge and perception of infection prevention and control. $J$ Hosp Infect 68(1): 92-4. doi: 10.1016/j.jhin.2007.10.013

Wang H, Fennie K, He G, Burgess J Williams AB (2003) A training programme for prevention of occupational exposure to bloodborne pathogens: impact on knowledge, behaviour and incidence of needle stick injuries among student nurses in Changsha, People's Republic of China. J Adv Nurs 41(2): 187-94.

Watterson L (2004) Monitoring sharps injuries: EPINet surveillance results. Nurs Stand 19(3): 33-8. doi: 10.7748/ns2004.09.19.3.33.c3701

Wicker S, Stirn AV, Rabenau HF, von Gierke L, Wutzler S, Stephan C (2014) Needlestick injuries: causes, preventability and psychological impact. Infection 42(3): 549-52. doi: 10.1007/s15010-014-0598-0

World Health Organization (2003) Sharps Injuries. Global Burden of Disease From Sharps Injuries to Health-Care Workers. WHO, Geneva
Worthington MG, Ross JJ, Bergeron EK (2006) Posttraumatic stress disorder after occupational HIV exposure: two cases and a literature review. Infect Control Hosp Epidemiol 27(2): 215-7. doi: 10.1086/501155

Yang YH, Wu MT, Ho CK et al (2004) Needlestick/sharps injuries among vocational school nursing students in southern Taiwan. Am J Infect Control 32(8): 431-5. doi: 10.1016/S0196655304004523

Yang YH, Liou SH, Chen CJ et al (2007) The effectiveness of a training program on reducing needlestick injuries/sharp object injuries among soon graduate vocational nursing school students in southern Taiwan.J Occup Health 49(5): 424-9

Yao WX,Wu YL, Yang B et al (2013) Occupational safety training and education for needlestick injuries among nursing students in China: intervention study. Nurse Educ Today 33(8): 834-7. doi: 10.1016/j. nedt.2012.02.004

Yao WX,Yang B,Yao C et al (2010) Needlestick injuries among nursing students in China. Nurse Educ Today 30(5): 435-7. doi: 10.1016/j. nedt.2009.09.018

Yassi A, McGill M (1991) Determinants of blood and body fluid exposure in a large teaching hospital: hazards of the intermittent intravenous procedure. Am J Infect Control 19(3): 129-35

Zhang MX,Yu Y (2013) A study of the psychological impact of sharps injuries on health care workers in China. Am J Infect Control 41(2): 186-7. doi: 10.1016/j.ajic.2012.02.023

Zungu L, Sengane M, Setswe KG (2008) Knowledge and experiences of needle prick injuries (NPI) among nursing students at a University in Gauteng, South Africa. S Afr Fam Pract 50(5): 48

\section{CPD reflective questions}

- Reflect on the principles of safely handling sharps, such as needles and glass, within the clinical placement and while simulating skills

- How might you develop your practice to prevent sharps injuries in the future?

- Consider how you might feel if you unfortunately sustained a sharps injury, and think about the support that you would expect from your colleagues, friends and organisation

\section{Fundamental Aspects of Infection Prevention and Control}

Infection prevention and control is a major aspect of healthcare provision and thus it is vita for all practitioners to understand how to ensure safe, hygienic and effective patient care in their daily practice. This practical, handy text aims to provide essential information on infection prevention, control and management in any health care setting.

The book will be an invaluable tool to help staff reduce avoidable health care associated infections. It provides healthcare practitioners with a basic understanding of infectious agents, their physiology, classifications and transmission. It also covers the clinical management of infections, presenting best practice guidelines and precautionary measures as well as useful tips and tools to safeguard patients from infections. In addition, it presents the practical considerations for the management and treatment of infections, such as staff roles and responsibilities, environmental hygiene, sterilization, management of invasive devices and much more.

The content is designed be clear, concise and highly practical. The user-friendly format features learning outcomes, checklists, tables, bullet points and practical examples throughout. Chapters include relevant case studies, reflective practice activities and discussion questions to aid learning.

ISBN-13: 978-1-85642-415-8; 234 x 156 mm; paperback; 250 pages; publication 2010; £24.99
Order your copies by visiting
or call our Hotline
www.quaybooks.co.uk +44 (0) 333800 1900*

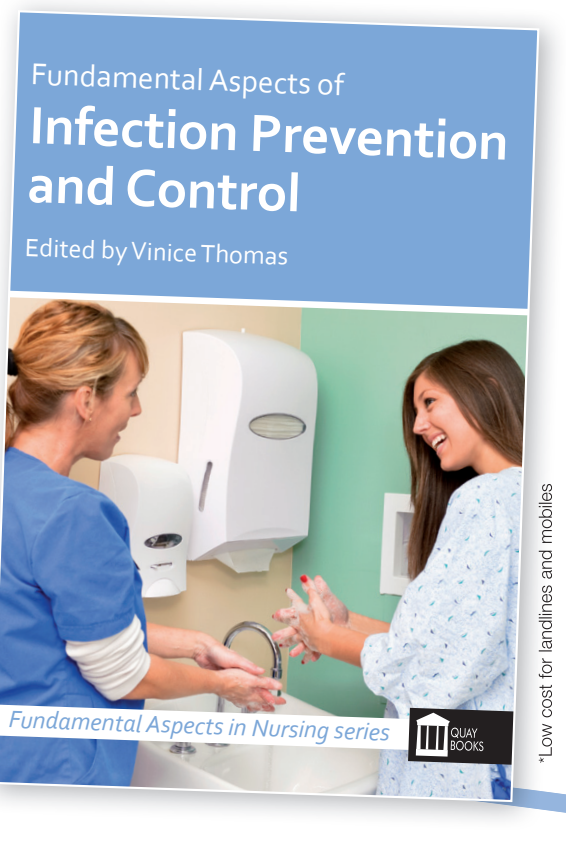


Table w1. The 40 studies included in the review

\section{Reference (country)}

study design

Albertoni et al (1992)

(Italy) Survey

Askarian et al (2012)

(Iran) Survey

Aslam et al (2010)

(Pakistan) Survey

Blackwell et al (2007)

(US) Survey

Cheung et al (2012)

(Hong Kong) Survey

Hussain et al (2012)

(India) Survey

Irmak and Baybuga (2011)

(Turkey) Survey

Karadağ (2010)

(Turkey) Survey

Kermode et al (2005)

(India) Survey

Kim et al (2001)

(Korea) Survey

Lachowicz and Matthews

(2009)

(South Africa) Survey

Li and Scott (2008)

(China) Survey

Lukianskyte et al (2011)

(Lithuania) Survey

McCarthy and Britton

(2000) Canada) Survey

Mengal et al (2008)

(Pakistan) Survey

Mitra et al (2010)

(India) Survey

Muralidhar et al (2010)

(India) Survey

Naidoo (2010)

(South Africa)

Phenomenological study

Ozer and Bektas (2012)

(Turkey) Survey

Petrucci et al (2009)

(Italy) Survey

Reis et al (2004b)

(Brazil) Survey

\section{Key findings}

9.5\% of 1164 first year students had had an NSI; $26 \%$ of 1612 second and third year student nurses had had an NSI ( $p<0.001$ )

75\% did not report their injury. Reasons were: not knowing the reporting mechanism; did not realise that all NSIs required reporting; did not know to whom to report the injury

$45 \%(n=36)$ of sample experiencing an NSI in a previous month were student nurses

A total of 9 out of 96 received an NSI which is a rate of $9.4 \%$. Only 4 out of 9 students (44.4\%) reported the incident; $22.2 \%$ (2 out of 9) students experiencing NSIs reported having only $3-5$ hours of sleep on the night before the incident; $33.3 \%$ ( $n=3$ ) of injuries occurred on a medical-surgical unit

Prevalence of $5.9 \%(n=52)$ of NSI/SIs over past 12 months. NSI location: $53.2 \%(n=25)$ on medical wards; $29.8 \%(n=14)$ on surgical wards. NSI devices: $75 \%(n=42)$ injection needles. Procedure: $27.8 \%(n=15)$ occurred when removing a needle cap. Other factors: $62.5 \%(n=35)$ blamed 'carelessness'. Reporting NSIs: $60.7 \%(n=34)$ chose not to report the NSI

$76.4 \%(n=68)$ were the cases of sharp instrument injuries in the past year. $60.2 \%(n=41)$ had had two episodes of the injury. 73.5\% $(n=50)$ of injuries occurred during IV/IM injection. 80.8\% ( $n=55)$ occurred with a hollow bore needle

$19.4 \%(n=60)$ said they had injuries from NSIs. The most common device was a syringe needle (54\%, $n=34)$, followed by glass items (33.3\%, $n=21)$. 60\% ( $n=36)$ occurred when giving IV/IM injections, followed by from a broken ampoule $(25 \% \mathrm{n}=15)$. The most common area of injury was the finger (81.4\%) Location: medical clinics $(43.3 \% n=26)$ and surgical clinics $(56.7 \% n=34)$. $68.3 \%$ $(n=41)$ NSIs were unreported

$35.5 \%$ of the students had received an NSSI. $66 \%(n=33)$ were caused by a broken ampoule or vial while. $28 \%(n=14)$ were caused by a syringe needle. $84 \%(n=42)$ did not report the incident

$48.1 \%$ of student nurses had had a percutaneous sharps injury within the last year

Student nurses had a better level of knowledge relating to 'avoiding injury from used needles' than medical students. Student nurses had a poor level of knowledge relating to 'putting the cap back on the used needle before disposing of it', but a better level of knowledge than medical students

$28.26 \%(n=13)$ of student nurses had sustained a sharps injury

Six respondents (3\%) had experienced an NSI

$78 \%(n=78)$ of student nurses had had an NSI. $59 \%(n=46)$ occurred in the procedures room; $15 \%(n=12)$ occurred in the patient's room. 49\% ( $n=39)$ occurred during breaking of the ampoule. $64 \%(n=50)$ were due to inattention/haste. $92 \%(n=72)$ did not report the incident

$14 \%(n=9)$ of 64 student nurses had had an NSI

12.8\% $(n=25)$ had had one NSI; $9.2 \%(n=18)$ had had two NSIs; 3.6\% $(n=7)$ had had more than two $9.1 \%(n=5)$ of those who were exposed to blood and blood products, did not reported the injury

$98.4 \%(n=187)$ had had an accidental needle prick. Only $18.4 \%(n=35)$ reported the injury to the authority

85.3\% $(n=64)$ had had a needlestick injury in the preceding year

Four themes: Traumatic incident-including 'account of the incident' and 'setting the scene'; Reaction to the traumatic incidentincluding 'physiological reaction', 'emotional reaction of the student and family', 'reaction to treatment' and 'reaction to nursing practice'; Intervening factors-including 'knowledge of student', 'knowledge of professional staff in service setting' and 'preparedness to practice'; Need for support-including 'support from family and friends', 'support from staff in service settings' and 'support from staff at the higher education institution

Overall prevalence rate of $33 \%(n=94) .14 .4 \%(n=41)$ occurred with a glass item. NSI prevalence was $31.4 \%(n=27)$ in the first year. NSI prevalence was $44.4 \%(n=28)$ in the second year. NSI prevalence was $39.4 \%(n=28)$ in the third year. NSI prevalence was $18.6 \%(n=13)$ in the fourth year. Most common cause: $10 \%(n=7)$ occurred with a glass item

First year students had a higher probability of skin and percutaneous contamination than those in the second and third years

$40 \%(n=50)$ reported to have been injured in some type of accident with cutting and piercing objects or had contact of biological material with their skin or mucosa . $51 \%(n=37)$ of injuries were caused by piercing objects; $44 \%$ of injuries were caused by cutting objects. The main objects causing accidents were needles; among cutting objects (ampoules, scissors, glass vials), medication ampoules were the most common. Most affected areas: $90.2 \%(n=65)$ occurred on the fingers . $22.2 \%(n=16)$ related to 'lack of attention/distraction; $13.9 \%(n=10)$ related to 'inexperience'. The students reported negative feelings of 'anger'; 'insecurity'; 'concern'; 'fear'; 'Iow self-esteem'; 'frustration'; 'incapacity'; 'incompetence'; 'fear of infection e.g. HIV' 
Salelkar et al (2010)

(India) Survey

Scaggiante et al (2013)

(Italy) Case study

\section{Schaffer (1997)}

(USA) Survey

Schmid et al (2007)

(Germany) Survey

Sharma et al (2010)

(India)

Survey

Shiao et al (2002)

(Taiwan) Survey

Small et al (2011)

(Namibia) Survey

Smith and Leggat (2005)

(Australia) Survey

Talas (2009)

(Turkey) Survey

Tetali and Choudhury

(2006)

(India) Survey

Trivedi et al (2013)

(India) Quasi-experiment

Unver et al (2012)

(Turkey) Survey

Vandijck et al (2008)

(Belgium) Survey

Wang et al (2003)

(China) Quasi-experiment

Yang et al (2004)

(Taiwan) Survey

Yang et al (2007)

(Taiwan) Quasi-experiment

Yao et al (2010)

(China) Survey

Yao et al (2013)

(China) Quasi-experiment

Zungu et al (2008)

(South Africa) Survey
$6.4 \%(n=3)$ student nurses had had a NSI in the previous year

$33 \%(n=1)$ of student nurses had reported the NSI

Student nurse injured on the second finger of the right hand when re-capping a 23-gauge needle after taking a blood sample. The source was a 72-year-old woman who was weakly positive for anti-HCV. Three months after the injury, a relevant increase in transaminases with a low viral replication activity was observed in the student, indicating HCV infection. She was treated with pegylated interferon plus ribavirin for 24 weeks. The student was 'cured' 6 months later

31 incidents of percutaneous exposure

20/68 student nurses consulted the occupational physician as a result of occupational exposure to blood or other body fluids, the vast majority of which were caused by NSSI

$94.2 \%(n=40)$ of student nurses had had one or more NSI (the highest of all other health workers) . $25 \%$ ( $n=10$ ) had had a NSI in the last month. $28.6 \%(n=12)$ had a NSI whilst re-capping. 38.8\% $(n=16)$ reported the NSI to their supervisor or senior

Prevalence rate was $61.5 \%(n=352) .42 .6 \%(n=150)$ were caused by a hollow bore syringe needle; $21.3 \%(n=75)$ were caused by a glass item; $14.8 \%(n=52)$ occurred during re-capping; $19.3 \%(n=68)$ happened when opening of ampoule or vial; $86.9 \%(n=306)$ were not reported

$25 \%(n=49)$ had had a NSI; $58.8 \%(n=20)$ were injured only once; $26.5 \%(n=9)$ were injured more than once; $45 \%(n=22)$ of those students who sustained an NSI never reported it; $27 \%(n=17)$ of all injuries occurred in clinics; $27 \%(n=17)$ of all injuries occurred in medical wards

13.9\% $(n=38)$ reported a NSI in the previous year. Prevalence: $4.3 \%$ (first year); $11.4 \%$ (in the second year); $40.4 \%$ (in the third year). $37 \%$ caused by a syringe; $22 \%$ caused by a glass item; $20 \%$ caused by an insulin syringe; $45 \%$ occurred in the skills laboratory. Of the 38 students reporting NSI, 15.8\% had had 2-5 events. 34\% of those reporting a NSI were injured while opening the cap; $26 \%$ of those reporting a NSI were injured when opening an ampoule. $39.5 \%$ of NSIs were not reported

$49 \%(n=230)$ reported sustaining NSSI. Most injured students $(63.5 \%)$ had had two or more NSSIs

The most frequent site was the hand (98.7\%). 29.3\% of injuries occurred in the second year, $36.1 \%$ in the third year and $34.3 \%$ in the fourth year. $43 \%(n=168)$ occurred with medical ampoules and serum bottles; $42 \%(n=166)$ occurred with hollow bore needles; $74 \%$ ( $n=169)$ happened on wards; $70 \%(n=160)$ reported that the cause was 'manual skills were under-developed'; $27 \%$ ( $n=62)$ reported that the cause was 're-capping a needle'; $56.1 \%(n=129)$ of NSSIs were unreported to their clinical instructor or hospital staff

Mean number of injuries per person per year was $1.9(S D=0.7) .25 \%(n=16)$ student nurses had had a sharps injury in the previous year; $55 \%$ of injuries were caused by re-capping . Non-reporting $(n=43)$

$100 \%$ had experience NSI by needles; $55 \%$ from blood-filled needles; $86 \%$ struck by stylet of IV catheter; $31 \%$ had NSI by surgical blade/scalpels. After training, there was a significant $(p=<0.001)$ improvement in knowledge of prevention and management of NSI

Proportion sustaining NSSIs: $56.5 \%(n=13)$ of second year students; $53.1 \%(n=17)$ of third years; $51.2 \%(n=44)$ of fourth years; $52.5 \%(n=74)$ of all years. Second years: $53.8 \%(n=7)$ were caused by injection needles; $84.6 \%(n=11)$ did not report the NSSI. Third years: $52.9 \%(n=9)$ when using an injection needle; $82.4 \%(n=14)$ did not report the NSSI. Fourth years: 43.1\% ( $n=19)$ caused by injection needle; $88.6 \%(n=39)$ did not report the NSSI

$10.5 \%$ of students reported at least one NSI. $71.2 \%$ of students officially documented the NSI

Knowledge of universal precautions increased with training. 1.42 injuries per student nurse year (95\% Cl 1.05, 1.87). Injuries occurred most commonly when giving an injection (24\%); the most common sources of sharps injuries were IV needles (44\%), and syringe needles $(32 \%)$

$50.1 \%(n=264)$ of responders sustained one or more NSSI. Average number of NSI/SIs per student was 8 times/year (4.9 NSIs/ year and $3.1 \mathrm{SIs} /$ year. The largest number occurred in internal medicine and surgery departments. $42.1 \%$ were caused by syringe needles; 39\% $(n=103)$ reported the incident

Pre-test: 1999: 50.1\% $(n=264)$ of students reported NSSI at least once in clinics during the internship training. Only 39\% reported the events. $50.5 \%(n=54)$ reported a NSSI. Average frequency of NSI/SI was 8.1/year. Post-test: NSI/SI decreased significantly to $25.2 \%(n=27)$. Average frequency of NSI/SI was 2.7 times/year. Reporting rates increased 1.5 times to $55.6 \%$

1144 NSIs in the 246 student nurses. Average of 4.65 events/student nurse. Surgery: $20.54 \%(n=235) .54 .07 \%(n=133)$ had had 2-5 injuries. 96.24\% $(n=1101)$ were not reported

Before education: average of 4.65 events/student of NSI. 1144 NSIs occurred in the 246 student nurses; surgery (235 events, 0.955 events/student); medicine (230 events, 0.935 events/student); $54.06 \%(n=133$ ) had had $2-5$ NSIs; $25.18 \%$ ( $n=288$ ) caused by student handling the needle; $96.24 \%(n=1101)$ were not reported After education: average 0.163 events/student; 40 NSIs in total; surgery 0.016 events/student; medicine (0.008 events/student; $2 \%(n=5)$ had $2-5$ NSIs; $12.5 \%$ ( $n=5)$ happened when handling the needle; $97.5 \%(n=39)$ reported the NSI

15.6\% ( $n=15)$ student nurses declared that they had experienced an NPI sometime during their clinical practice. Only $7.3 \%$ of respondents had reported the incident. Reasons for non-reporting: $41.1 \%(n=3)$ due to fear of HIV testing; $31.7 \%$ ( $n=2.3)$ due to fear of disciplinary action; $13.6 \%(n=1)$ due to 'did not know where/to whom to report; $13.6 \%(n=1)$ due to 'fear of confidentiality' 